\title{
Intermittent or Continuous Therapy of Experimental Meningitis Due to Streptococcus pneumoniae in Rabbits: Preliminary Observations on the Postantibiotic Effect in Vivo
}

\author{
Merle A. Sande,* Oksana M. Korzeniowski, $\uparrow$ \\ George M. Allegro, Robert O. Brennan, $\ddagger$ \\ Otokar Zak, $\S$ and W. Michael Scheld
}

From the Department of Internal Medicine, University of
Virginia School of Medicine, Charlottesville, Virginia; and
Ciba-Geigy, Basel, Switzerland

\begin{abstract}
The relative effectiveness of bolus vs. constant intravenous administration of equivalent doses of penicillin $\mathrm{G}$ in killing bacteria in vivo was studied in a rabbit model of meningitis due to Streptococcus pneumoniae. Samples of cerebrospinal fluid (CSF) and serum were obtained from 30 rabbits at intervals of $\leqslant 8 \mathrm{hr}$ after treatment for determination of antibiotic concentrations and titers of viable bacteria in the CSF. When penicillin $\mathrm{G}$ was given by continuous infusion ( $10^{5}$ units/hr after an initial $10^{5}$-unit loading dose), concentrations of drug in serum and CSF reached a steady state in $1 \mathrm{hr}$. With intermittent bolus administration of $4 \times 10^{5}$ units every $4 \mathrm{hr}$, higher peak and lower trough concentrations were achieved, and these concentrations paralleled those in the CSF. Although an initial acceleration in bactericidal rate was observed with the bolus infusion between the first and second hour of therapy, after the second hour the rate of bacterial killing was identical for the two methods of administration. The duration of therapy required for sterilization of the CSF was dependent only on the bacterial count before treatment and not on the mode of drug administration. The effect of single bolus intravenous administration of ampicillin was examined in experimental pneumococcal meningitis. Ampicillin was given at various dosages $(3.25-62.5 \mathrm{mg} / \mathrm{kg}$ ), and frequent samples of CSF were obtained for determination of concentrations of pneumococci and ampicillin. A long postantibiotic effect was observed in the CSF of all animals, and this effect consistently was longer than that observed in vitro.
\end{abstract}

The question of the most effective mode of administration of $\beta$-lactam antibiotics for treatment of severe bacterial infections is controversial. Commonly used regimens are largely empirical and are based on pharmacokinetic parameters (often only available from studies done with normal volunteers), knowledge of susceptibility characteristics of the suspected pathogen, and tradition. Parenteral therapy is preferred, but unpredictable absorption (e.g., shock) and clotting abnormalities may make the im route unreliable. Continuous iv administration produces a relatively fixed concentration of the antibiotic over time. Intermittent, or bolus, administration produces high initial con-

Please address requests for reprints to $\mathrm{Dr}$. W. Michael Scheld, Box 385, Division of Infectious Diseases, University of Virginia Medical Center, Charlottesville, Virginia 22908.

*Present address: Department of Medicine, University of California, San Francisco, San Francisco General Hospital, Room 4-H22, San Francisco, California 94101.

$\dagger$ Present address: Department of Internal Medicine, Medical College of Pennsylvania, Philadelphia, Pennsylvania 19104. $\ddagger$ Present address: Department of Internal Medicine, Johns Hopkins School of Medicine, Baltimore, Maryland 21233. §Present addess: Ciba-Geigy, Basel, Switzerland. centrations in serum that are followed by a rapid fall in levels of drug. Both intermittent and continous modes of administration have their advocates, whose opinions usually are based on studies that examined the effect of the mode of antibiotic administration on survival of animals with experimental infections [1-3]. Other studies have approached this problem by examining the dynamics of penetration of antibiotics into restricted sites as a function of the mode of drug administration [4, 5]. None of these investigations have examined the kinetics of bacterial stasis and killing, factors that might influence the rate of response to therapy.

Both types of regimens usually are adjusted to achieve concentrations of drug in serum above the MIC for the duration of therapy. However, clinical experience suggests that administration of these large doses may not be necessary. Pneumococcal pneumonia can be cured with only $8 \times 10^{3}$ to $1.2 \times 10^{4}$ units of penicillin G given every $12 \mathrm{hr}$ [6], despite concentrations of drug in tissue below the MIC. Cure of scarlet fever has occurred when penicillin was detectable in the serum for only $6 \mathrm{hr}$ per day [7]. Eagle et al. $[1,2,8]$ eradicated experi- 
mental streptococcal infections, despite antibiotic levels in tissue below the MIC during each treatment interval; they ascribed this result to a persistent effect of the drug on the organism, a phenomenon described by Parker et al. more than 30 years ago $[9,10]$. The postantibiotic effect has been clarified further by in vitro studies $[11,12]$, in which short-term exposure of Staphylococcus aureus or Escherichia coli to various antibiotics at or above the MIC produced a continued postantibiotic effect (decreased or stable bacterial counts) for various periods of time after removal of the antibiotic. Even subinhibitory levels of antibiotics can alter the growth rate and morphology of bacteria [13] and may modify important host defense mechanisms $[14,15]$. Previous exposure of $E$. coli to sub-MIC levels of chloramphenicol resulted in a prolonged decline in bacterial concentrations after exposure of the culture to leukocytes, antibody, and complement in vitro [12]. Thus, in vivo, contact of the organism with subtherapeutic concentrations of drug may potentiate host defenses and play a role in outcome of therapy. However, these kinetic concepts have not as yet been demonstrated in vivo.

We have used a rabbit model of pneumococcal meningitis to study these problems. The purposes of our investigations were $(l)$ to compare the effect of continuous vs. intermittent iv administration of penicillin on the kinetics of drug concentration and the rate of bacterial killing in the CSF in vivo, and (2) to examine the sequence and duration of bactericidal and bacteriostatic effects in vivo produced by a single bolus infusion of ampicillin.

\section{Materials and Methods}

Streptococcus pneumoniae. A strain of $S$. pneumoniae type 3 originally isolated from the blood and CSF of an adult with meningitis and previously characterized in our laboratory [16] was used. The strain was grown (from the same stock culture on glass beads) in trypticase soy broth (TSB; Difco Laboratories, Detroit, Mich.) supplemented with $5 \%$ defibrinated sheep blood for $18 \mathrm{hr}$ at $37 \mathrm{C}$ in an atmosphere of $10 \%$ $\mathrm{CO}_{2}-90 \%$ air. Before inoculation the culture was centrifuged at $200 \mathrm{~g}$. for $5 \mathrm{~min}$ for removal of erythrocytes, centrifuged again at $2,000 \mathrm{~g}$ for 15 min, washed twice in $0.9 \% \mathrm{NaCl}$, and suspended in $2.0 \mathrm{ml}$ of $0.9 \% \mathrm{NaCl}$. This procedure provided an inoculum of $10^{7} \mathrm{cfu}$, which was verified for each experiment by quantitative plating on trypticase soy agar (TSA) pour plates.

In vitro studies The MICs and MBCs of penicillin and ampicillin were determined by a microtiter method in heart infusion broth with inocula of $10^{4}$ or $10^{6} \mathrm{cfu}[16,17]$.

In addition, the effects of in vitro exposure of the organism to ampicillin for short periods were examined by quantitative "time-kill" methods. $S$. pneumoniae type 3 was grown for $18 \mathrm{hr}$ in TSB plus $5 \%$ sheep blood at $37 \mathrm{C}$ in $10 \% \mathrm{CO}_{2}-90 \%$ air. This culture was diluted $10^{-4}$, transferred to fresh media, and incubated under identical conditions for $5 \mathrm{hr}$ until the culture reached log phase. A $10^{-1}$ dilution $(1.0 \mathrm{ml})$ of this culture was divided into five $25-\mathrm{ml}$ cotton-stoppered flasks, each containing $10 \mathrm{ml}$ of fresh media. After incubation for $1 \mathrm{hr}$, quantitative titers of bacteria were measured by 10 -fold dilutions on TSA pour plates supplemented with sheep blood. Standardized ampicillin powder (Wyeth Laboratories, Philadelphia, Pa.) was dissolved in $0.9 \% \mathrm{NaCl}$ and added to the flasks; the final concentrations of drug were 0.01 , $0.1,1.0$, and $10 \mu \mathrm{g} / \mathrm{ml}$. One flask contained no antibiotic and served as a control. After administration of ampicillin, all flasks were incubated at 37 $\mathrm{C}$ in $10 \% \mathrm{CO}_{2}-90 \%$ air with continuous shaking for $2 \mathrm{hr}$. Antibiotic was then removed by centrifugation $(2,000 \mathrm{~g}$ for $10 \mathrm{~min})$; the pelleted bacteria were washed three times with $10 \mathrm{ml}$ of $0.9 \% \mathrm{NaCl}$ and suspended in fresh TSB containing sheep blood. Bacterial concentrations were counted with use of quantitative pour plates at this time, then every hour for $3 \mathrm{hr}$, and every $2 \mathrm{hr}$ for $18 \mathrm{hr}$.

Rabbit model of meningitis. Pneumococcal meningitis was produced in New Zealand white rabbits or Russian hares weighing $2-3 \mathrm{~kg}$ as described previously $[16,17]$. Anesthesia was induced with $30 \mathrm{mg}$ of sodium pentobartital (Barber Veterinary Supply Co., Richmond, Va.) administered iv, and a dental acrylic "helmet" was attached to the animal's skull to facilitate immobilization in a stereotaxic frame. Several days later, the animals were anesthetized again, placed in the stereotaxic frame, and inoculated intracisternally with $10^{7}$ cfu of $S$. pneumoniae via a Quincke spinal needle ( 25 gauge $\times 31 / 2$ in) held in a geared electrode introducer. All therapeutic experiments 
were performed 16-18 hr after inoculation when the rabbits had meningitis, as manifested by fever (temperature, $>39.6 \mathrm{C}$ ), lethargy, and other neurologic signs: cerebrospinal fluid (CSF) pleocytosis $(\geqslant 95 \%$ polymorphonuclear leukocytes [PMNs]) and bacterial titers in CSF that ranged from $10^{4}$ to $>10^{8} \mathrm{cfu} / \mathrm{ml}$. Only animals with concentrations of bacteria in CSF of $>10^{4} \mathrm{cfu} / \mathrm{ml}$ $(\geqslant 95 \%$ of all inoculated rabbits) were included for analysis. If untreated, this degree of meningitis is uniformly fatal within 24-36 hr.

Experimental design: intermittent vs. continuous penicillin therapy. After reinduction of light anesthesia with sodium pentobarbital, indwelling femoral arterial and venous catheters (Intramedic $^{\circledR}$ polyethyene tubing 7420 , Clay-Adams, Parsippany, N.J.) were placed, and the animals positioned in the stereotaxic frame. Two groups of 15 animals each received iv penicillin G (Bristol Laboratories, Syracuse, N.Y.) by the intermittent or continuous mode of administration. The intermittent group received $4 \times 10^{5}$ units given as a bolus over $2 \mathrm{~min}$; two such doses were given, $4 \mathrm{hr}$ apart. The animals in the continuously treated group were treated iv with an initial loading dose of $10^{5}$ units, followed by $10^{5}$ units $/ \mathrm{hr}$ given via a syringe infusion pump (model 352; Sage Instruments, White Plains, N.Y.) for the 8 hr of observation. Samples of serum and CSF were taken simultaneously at $0,1,2,4,5,6$, and $8 \mathrm{hr}$ of therapy. CSF was withdrawn in $0.3-\mathrm{ml}$ aliquots, of which $0.2 \mathrm{ml}$ was used for quantitative culture and $0.1 \mathrm{ml}$ for determination of the penicillin concentration. Samples for culture were treated with penicillinase $(5,000 \mathrm{units} / \mathrm{ml}$ of CSF) for inactivation of the residual penicillin and either were plated directly without dilution $(0.1 \mathrm{ml})$ or were serially diluted and quantitatively titrated on TSA blood agar pour plates, which were incubated in $10 \% \mathrm{CO}_{2}-90 \%$ air at $37 \mathrm{C}$ for $24 \mathrm{hr}$. Serum samples, in $1.0-\mathrm{ml}$ aliquots from the femoral artery catheter, were used for determinations of the penicillin concentration.

Single-dose ampicillin therapy. Procedures identical to those described above were followed in these experiments, except that ampicillin was used instead of penicillin and the drug was given as a single iv bolus in one of the following dosages: $3.25,6.5,12.5,25,37.5$, or $62.5 \mathrm{mg} / \mathrm{kg}$. Samples of CSF and serum were withdrawn for determination of quantitative bacterial counts and ampicillin concentrations at intervals of $0.25,0.5$, $0.75,1,1.5,2,2.5,3,4,6$, and $8 \mathrm{hr}$ after administration of ampicillin and at frequent intervals thereafter for up to $24 \mathrm{hr}$ or until the animal died, whichever occurred first.

Antibiotic assay. Concentrations of penicillin and ampicillin were determined by an agar well diffusion technique [18]. Assay plates (diameter, $105 \mathrm{~mm}$ ) were prepared by the addition of a Bacillus subtilis spore suspension $(0.2 \mathrm{ml})$ to $100 \mathrm{ml}$ of antibiotic medium no. 1 (Difco). Wells of $\sim 0.6 \times$ $0.6 \mathrm{~cm}$ were cut and filled with $\sim 0.03 \mathrm{ml}$ of serum or CSF. All samples and standards were tested in triplicate. Serum standards consisted of known concentrations of penicillin or ampicillin dissolved in pooled rabbit serum. CSF standards were prepared in $0.9 \% \mathrm{NaCl}$ since identical zones were observed for standards prepared in uninfected rabbit $\mathrm{CSF}$, infected rabbit $\mathrm{CSF}$, or $0.9 \% \mathrm{NaCl}$. Infected rabbit CSF did not produce a zone of inhibition in this assay. The smallest concentration of drug that could be measured accurately was 0.1 $\mu \mathrm{g} / \mathrm{ml}$.

\section{Results}

In vitro susceptibility. All MICs and MBCs of penicillin were $0.06 \mu \mathrm{g} / \mathrm{ml}$ for the test strain at both inocula examined, i.e., $10^{4}$ or $10^{6} \mathrm{cfu} / \mathrm{ml}$. Corresponding MICs and MBCs of ampicillin were $0.06-0.08 \mu \mathrm{g} / \mathrm{ml}$ at $10^{4} \mathrm{cfu} / \mathrm{ml}$ and $0.1-0.125$ $\mu \mathrm{g} / \mathrm{ml}$ at $10^{6} \mathrm{cfu} / \mathrm{ml}$.

(l) Intermittent vs. continuous penicillin therapy. Serum and CSF penicillin concentrations. The concentrations of penicillin in the serum and CSF clearly reflect the mode of drug administration (figure 1). With continuous iv infusion, a relatively steady-state concentration of penicillin in the serum was achieved $1 \mathrm{hr}$ after therapy began. The mean ( $\pm \mathrm{SD}$ ) levels of penicillin were $12.8 \pm$ $1.8 \mu \mathrm{g} / \mathrm{ml}$ at $2 \mathrm{hr}, 13.9 \pm 1.4 \mu \mathrm{g} / \mathrm{ml}$ at $4 \mathrm{hr}, 12.5 \pm$ $2.0 \mu \mathrm{g} / \mathrm{ml}$ at $6 \mathrm{hr}$, and $7.9 \pm 1.7 \mu \mathrm{g} / \mathrm{ml}$ at $8 \mathrm{hr}$; the overall mean was $11.8 \mu \mathrm{g} / \mathrm{ml}$. Administration of penicillin by intermittent (bolus) infusion produced mean peak levels of drug in serum of $9.9 \pm$ $2.5 \mu \mathrm{g} / \mathrm{ml}$ and $19.6 \pm 4.1 \mu \mathrm{g} / \mathrm{ml}$ at 1 and $5 \mathrm{hr}$, respectively, and mean trough levels of $0.7 \pm 0.2$ $\mu \mathrm{g} / \mathrm{ml}$ and $1.8 \pm 0.6 \mu \mathrm{g} / \mathrm{ml}$ at 4 and $8 \mathrm{hr}$, respectively.

The concentration of penicillin in CSF paralleled the concentration in serum (figure 1). A rel- 
Figure 1. Mean concentration of penicillin in the serum and cerebrospinal fluid of rabbits with pneumococcal meningitis during therapy with equivalent doses of penicillin by continuous $(0---O)$ or intermittent $(\bullet)$ iv infusion. Bars represent SE.

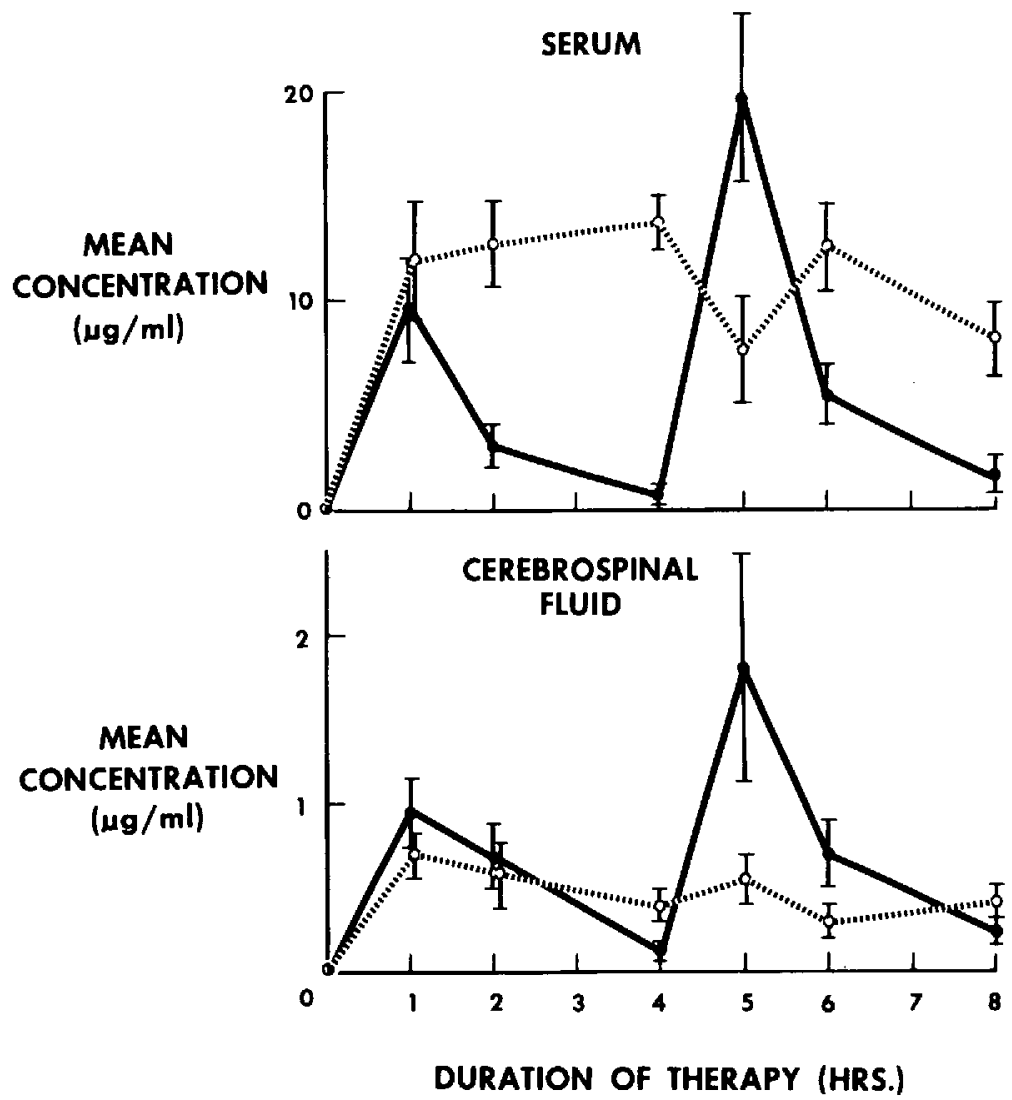

penicillin were examined at 1- and 2-hr intervals (figure 2). Before the start of therapy, the mean bacterial titers in CSF did not differ between experimental groups. Mean concentrations of $10^{5.25}$ $\pm 1.06 \mathrm{cfu} / \mathrm{ml}$ and $10^{5.27} \pm 1.21 \mathrm{cfu} / \mathrm{ml}$ were found for the continuous and intermittent groups, respectively $(P>0.1)$. With the initiation of therapy, a rapid bactericidal effect was seen in each group. This bactericidal effect was equivalent at all time periods except for the interval between the first and second hour of treatment. In the first hour of treatment, the mean decline in bacterial titers in CSF was $10^{0.20} \pm 0.29 \mathrm{cfu} / \mathrm{ml}$ for the continuous group and $10^{0.06} \pm 0.17$ for the intermittent group $(P>0.1)$. However, between 1 and $2 \mathrm{hr}$ of treatment, the mean bacterial titer of the continuous group had decreased by only $10^{0.48} \pm 0.31$ $\mathrm{cfu} / \mathrm{ml}$, whereas the mean titer of the intermittent or bolus group was reduced by $10^{1.25} \pm 0.26$ $\mathrm{cfu} / \mathrm{ml}(P<0.05)$. After the second hour of treatment, the magnitude of bacterial killing was the same for both modes of drug administration. In each group, mean titers of bacteria in CSF decreased by $\sim 1.5$ logs during every 2 -hr interval. ter of bacteria in CSF of animals receivin either continuous or intermittent infusions of 


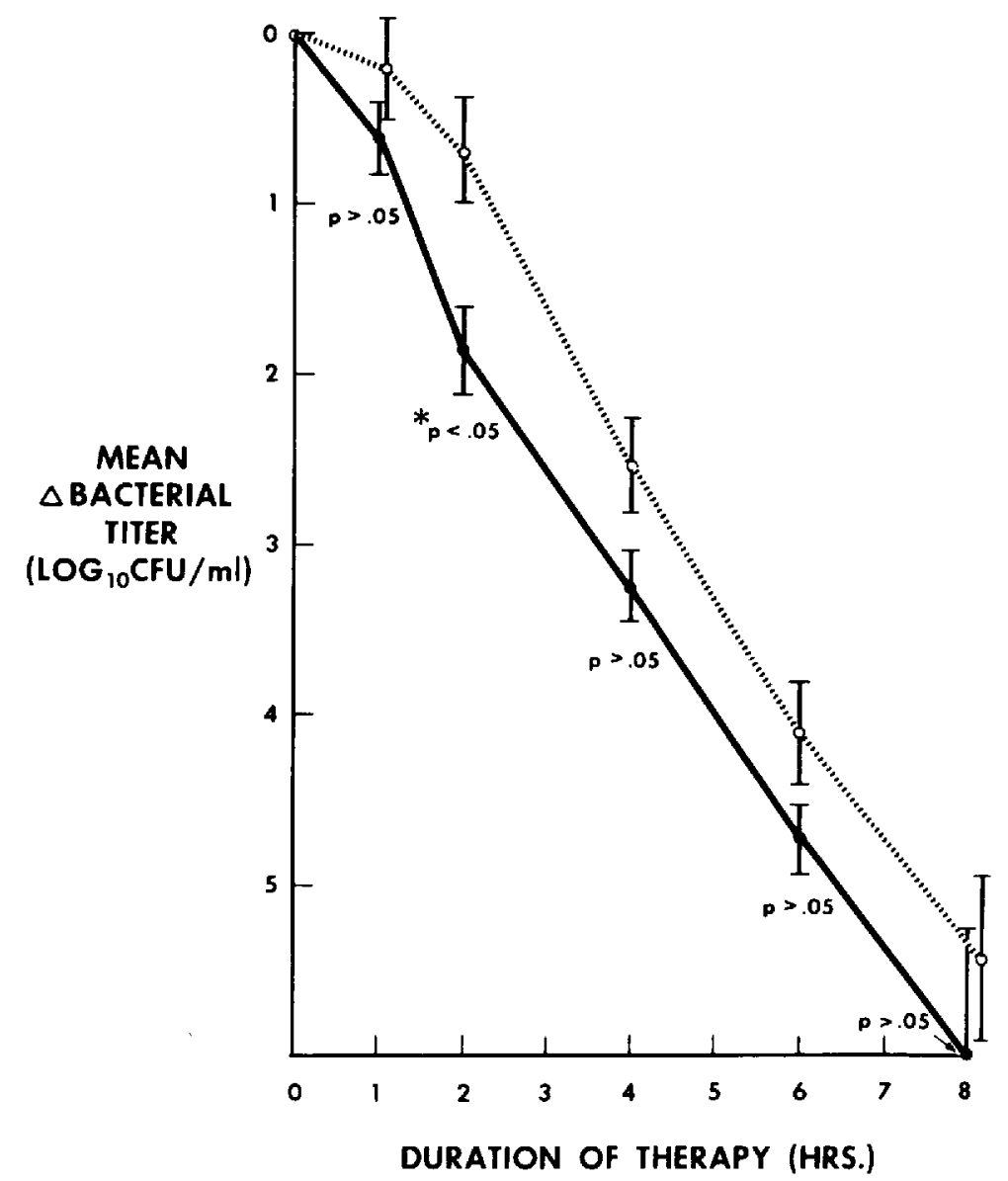

Figure 2. Magnitude of bacterial killing in the cerebrospinal fluid of rabbits with pneumococcal meningitis during therapy with equivalent doses of penicillin by continuous (O---O) or intermittent ( iv infusion.

Rate of bacterial killing. The rate of bacterial killing in the CSF for the two experimental groups was compared by least-squares regression analysis (figure 3). Both experimental groups showed a logarithmic first-order diminution in bacterial titer. The slopes of the lines representing continuous and intermittent modes of treatment were -0.613 and -0.612 , respectively, and thus nearly were identical $(P>0.05)$.

The effect of the initial (before therapy) bacterial titer in the CSF on the rate of bacterial killing was examined (figure 4). The 30 infected experimental animals were divided arbitrarily into two groups: those with initial titers of $\geqslant 10^{5} \mathrm{cfu} / \mathrm{ml}$ and those with titers of $<10^{5} \mathrm{cfu} / \mathrm{ml}$. The rates of bacterial killing produced by the intermittent or continuous mode of penicillin administration were compared for each group by least-squares regression analysis. Sixteen animals had initial titers of $\geqslant 10^{5} \mathrm{cfu} / \mathrm{ml}$. Eight received continuous and eight, intermittent penicillin therapy. Fourteen animals had bacterial titers in CSF of $<10^{5} \mathrm{cfu} / \mathrm{ml}$, and seven received either continuous or intermittent infusion, respectively. Again, a logarithmic firstorder diminution in titer was seen in all four groups, and the slopes $(m)$ of these lines did not differ statistically. Thus, the initial bacterial titer did not influence the rate of bacterial killing in this experimental model.

It is also evident that, whatever the mode of drug administration, $8 \mathrm{hr}$ of therapy was adequate to sterilize the CSF of animals with initial bacterial titers of $<10^{5} \mathrm{cfu} / \mathrm{ml}$. At equivalent rates of killing, animals with higher titers of bacteria in the CSF would therefore require a longer duration of treatment (extrapolated to a mean of 9-10 hr) in order to achieve sterility. This fact was confirmed when the therapeutic outcome was examined.

Outcome of therapy. Administration of penicillin for $8 \mathrm{hr}$ by either the continuous or intermittent mode resulted in similar outcomes 
Figure 3. Rate of bacterial killing in the cerebrospinal fluid of rabbits with pneumococcal meningitis during therapy with equivalent doses of penicillin by continuous $(0-\ldots)$ or intermittent (๑) iv infusion. Values were obtained by leastsquares regression analysis.

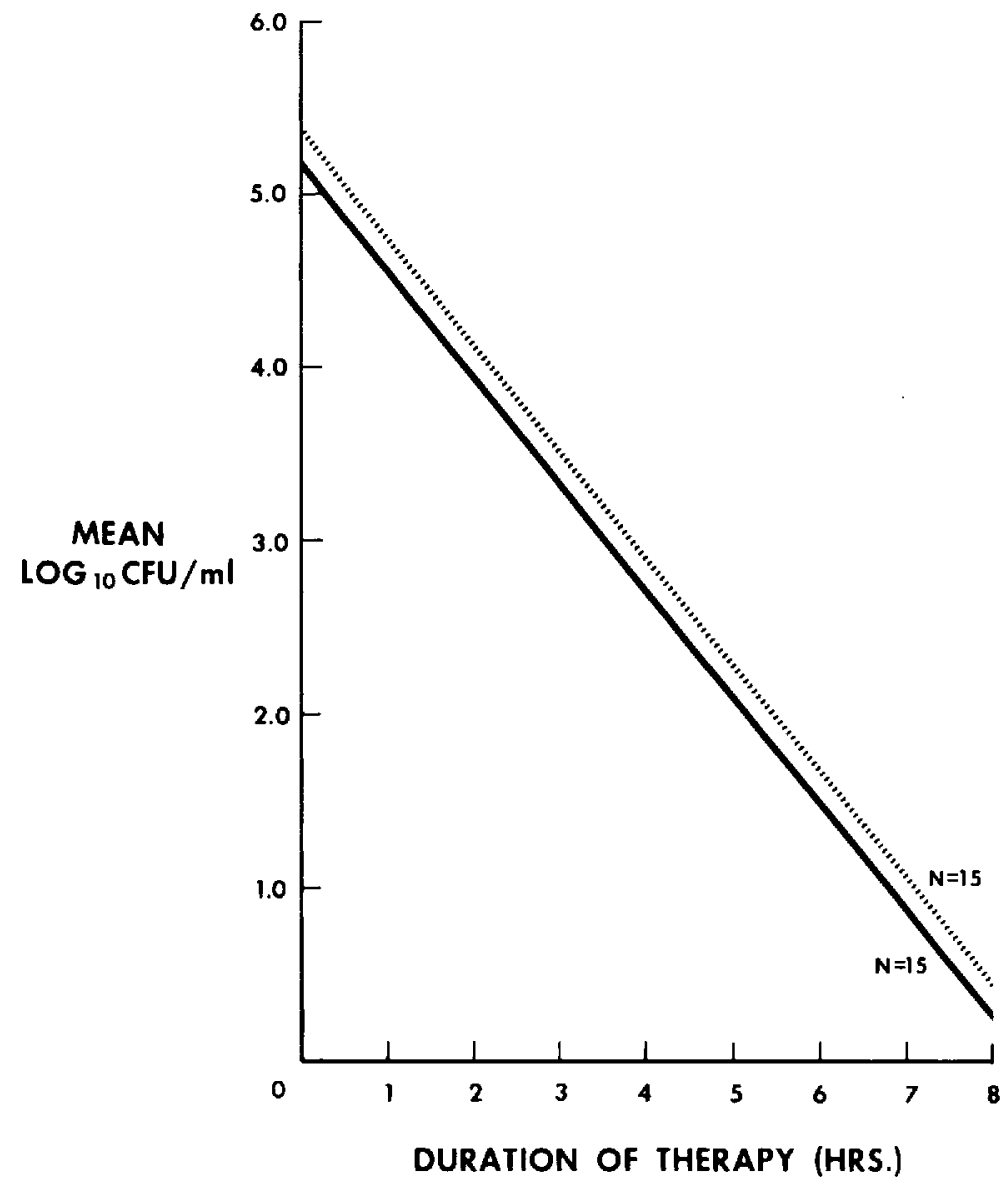

S. pneumoniae to superinhibitory concentrations of ampicillin $(0.1,1.0$, or $10 \mu \mathrm{g} / \mathrm{ml})$ for $2 \mathrm{hr}$ resulted in a reproducible postantibiotic effect (figure 5). This effect was reflected by the lag phase after removal of ampicillin from the flasks by centrifugation during which time no bacterial multiplication was demonstrated. This interval, defined as the time necessary to reach a bacterial concentration $1 \mathrm{log} / \mathrm{ml}$ greater than that observed at the end of centrifugation was 6.5, 6.7, and 7.6 $\mathrm{hr}$ for $0.1,1.0$, and $10 \mu \mathrm{g}$ of ampicillin $/ \mathrm{ml}$, respectively. A maximal effect was apparent at ampicillin concentrations that exceeded the MIC. In contrast, when the organism was exposed to $0.01 \mu \mathrm{g}$ of ampicillin $/ \mathrm{ml}$ for $2 \mathrm{hr}$, a concentration well below the MIC of $0.08 \mu \mathrm{g} / \mathrm{ml}$, bacterial concentrations increased steadily and were indistinguishable from those observed in control flasks without antibiotic (figure 5). In the presence of $0.01 \mu \mathrm{g}$ of ampicillin $/ \mathrm{ml}$, bacterial titers increased by $2-3$ logs in the first 4-6 hr and then remained stable at
(2) Single-dose ampicillin therapy. Quantita- tive "time-kill" experiments in vitro. Exposure of

Four partially treated animals (e.g, continuous administration of penicillin for $4 \mathrm{hr} ; 10^{5}$ units $/ \mathrm{hr}$ ) were allowed to relapse and succumbed to infection within $24 \mathrm{hr}$. Thus, no spontaneous clearing of meningitis occurred. 


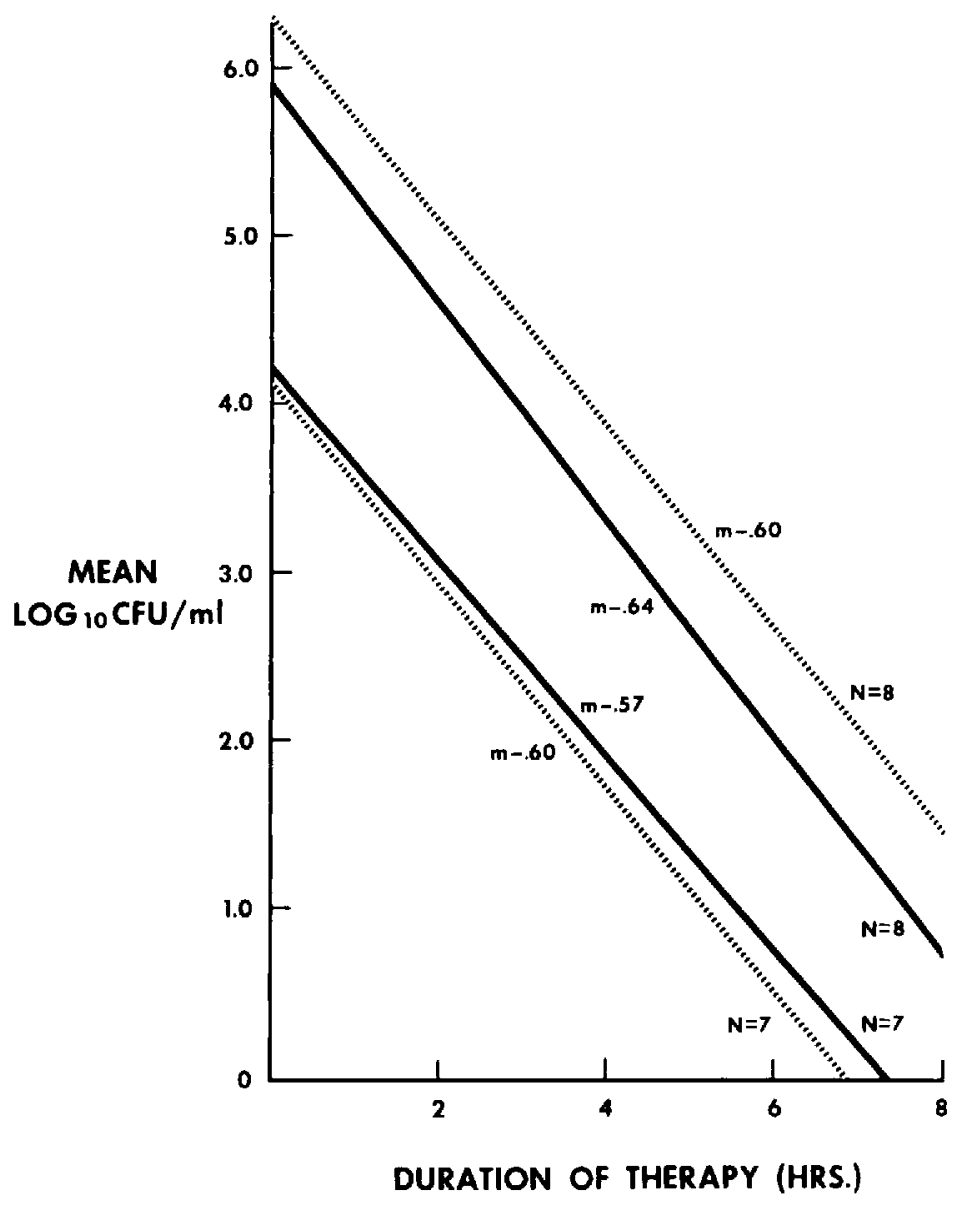

Figure 4. Rate of bacterial killing in CSF of rabbits with pneumococcal meningitis during therapy with equivalent doses of penicillin by continuous $\left(0-0^{-}\right)$or intermittent $(-)$ ) iv infusion. Experimental animals were grouped by pretreatment bacterial titers in CSF of $>10^{s}$ $\mathrm{cfu} / \mathrm{ml}$ (mean for continuous group, $10^{6.05} \pm 0.97 \mathrm{cfu} / \mathrm{ml}$; mean for intermittent group, $10^{5.86} \pm 1.12$ $\mathrm{cfu} / \mathrm{ml}$ ) or of $<10^{5} \mathrm{cfu} / \mathrm{ml}$ (mean for continuous group, $10^{4.37} \pm 0.77$; mean for intermittent group, $10^{4.56} \pm$ $0.27 \mathrm{cfu} / \mathrm{ml}$ ).
$10^{8}$ and $10^{9} \mathrm{cfu} / \mathrm{ml}$ for the duration of the experiments.

Despite this prolonged postantibiotic effect, all flasks demonstrated an increase in bacterial concentrations and were equivalent to controls by 10-12 hr after removal of the drug. In contrast, when flasks containing $S$. pneumoniae were continuously incubated with stable superinhibitory concentrations of ampicillin $(0.1,1.0$, or 10 $\mu \mathrm{g} / \mathrm{ml}$ ), all cultures were sterile by $18 \mathrm{hr}$.

In vivo. After induction of pneumococcal meningitis in rabbits by procedures identical with those utilized for the penicillin experiments, a series of animals were treated with a single iv bolus of ampicillin at dosages that varied over a wide range $(3.25-62.5 \mathrm{mg} / \mathrm{kg}$ ). These dosages were chosen to achieve measurable peak concentrations of ampicillin in CSF that were below, approximately equal to, and well above the MIC for the test strain $(\sim 0.1 \mu \mathrm{g} / \mathrm{ml})$. Bacterial titers declined in all treated rabbits. In contrast, the concentra- tion of bacteria in the CSF increased in all control (untreated) animals; mean increases of 0.16 and $2.11 \mathrm{logs}$ were observed after 8 and $24 \mathrm{hr}$, respectively.

A postantibiotic effect, defined as a continued cidal and static period after the concentration of

Table 1. Results of penicillin treatment $(8 \mathrm{hr})$ of experimental meningitis due to Streptococcus pneumoniae in rabbits: comparison of intermittent vs. continuous administration.

\begin{tabular}{lcc} 
Rabbits & Continuous & Intermittent \\
\hline $\begin{array}{l}\text { No. with sterile CSF after } \\
\text { treatment/total no. }\end{array}$ & $10 / 15$ & $11 / 15$ \\
$\begin{array}{l}\text { No. with sterile CSF after } \\
\text { treatment and } \\
\text { Initial bacterial titer } \\
\quad \begin{array}{l}<10^{5} \mathrm{cfu} / \mathrm{ml} \\
\text { Initial bacterial titer } \\
\geqslant 10^{\prime} \text { cfu/ml }\end{array}\end{array}$ & $7 / 7$ & $7 / 7$ \\
\end{tabular}

NOTE. $\quad$ CSF $=$ cerebrospinal fluid. 
Figure 5. Concentration $\left(\log _{10} \mathrm{cfu} /\right.$ $\mathrm{ml}$ ) of Streptococcus pneumoniae vs. time before, during, and after exposure to ampicillin in vitro. Exposure interval $(1-3 \mathrm{hr})$ is indicated by the cross-hatched bar (upper left). Concentrations of ampicillin $(\mu \mathrm{g} / \mathrm{ml})$ are as follows: $(0-0)=$ control (no ampicillin); (๑- $)=0.01$; $(\bullet---0)=0.1 ;(\Delta--\Delta)=1.0$; and $(\triangle \longrightarrow$ ) $=10$.

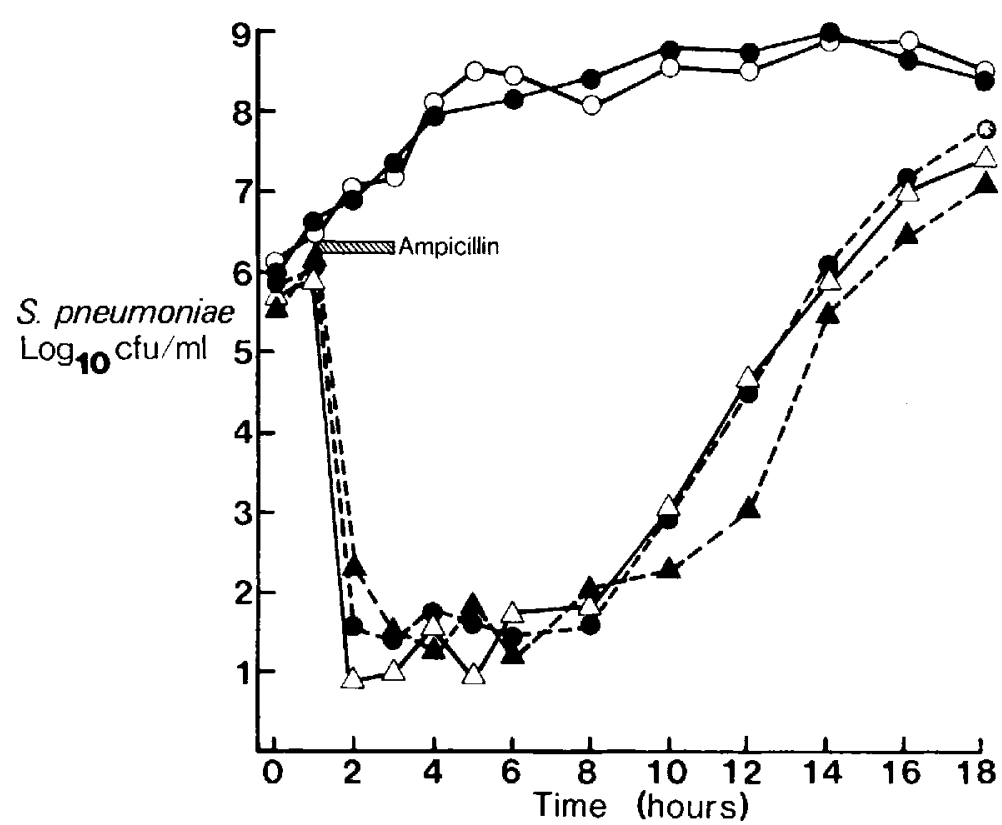

tance in the therapy of bacterial meningitis: (I) the influence of mode of drug administration (continuous vs. intermittent bolus) on antibiotic pharmacokinetics within the CSF, bactericidal activity, kinetics of bacterial killing in vivo, and therapeutic outcome in experimental pneumococcal meningitis; and (2) the influence of a short duration of exposure to ampicillin of bacteria in the CSF on the development of a postantibiotic effect in vivo. When equivalent therapeutic doses of penicillin

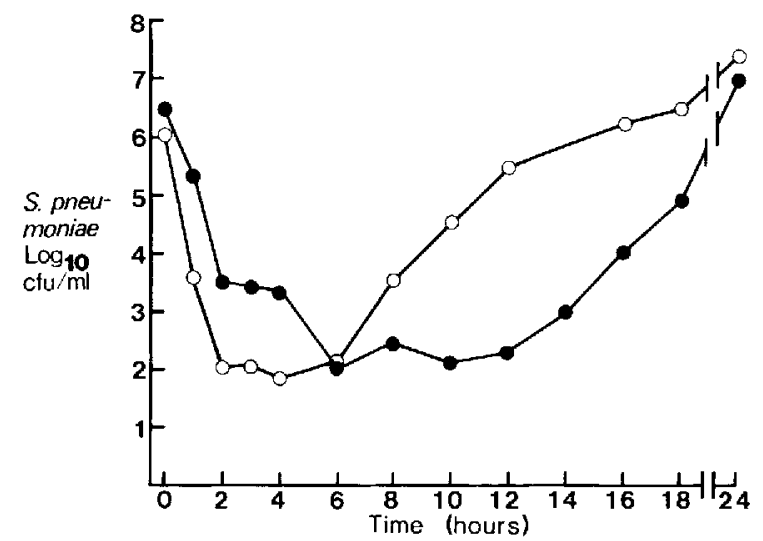

Figure 6. Counts of bacteria (ordinate) in two representative animals with experimental pneumococcal meningitis treated with a single dose of ampicillin plotted vs. time after injection (abscissa). The area under the curve for concentration of ampicillin in cerebrospinal fluid

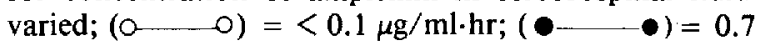
$\mu \mathrm{g} / \mathrm{ml} \cdot \mathrm{hr}$.

\section{Discussion}

This study examined two areas of potential impor- 
were employed, the results in this experimental model were essentially identical for both continuous and intermittent therapy. A postantibiotic effect in vivo was demonstrated when the single bolus of ampicillin was given; this effect also was present after exposure to near or subinhibitory concentrations of ampicillin.

The choice of the most effective mode of antibiotic administration in serious infections has been a subject of continuous debate. In studies of mice with streptococcal peritoneal infections, where survival was used as a measure of treatment outcome, the avoidance of long periods of subinhibitory concentrations of penicillin in the serum appeared critical [8]. Although the actual mode of drug administration was irrelevant in this study, the findings tended to support advocates of continuous drug administration.

Arguments also have been made in favor of intermittent iv injections of antibiotic, especially in the treatment of bacterial endocarditis [19]. The resultant higher levels of drug achieved in blood with this mode of administration theoretically would allow increased diffusion of the antimicrobial agent into an infected vegetation. Recently, Barza et al. observed an increased accumulation of ampicillin within sc fibrin clots in rabbits after intermittent as compared to continuous administration [4]. In addition, it has been postulated that brief periods of low concentrations of antibiotic might permit bacterial multiplication and, thereby, enhance the susceptibility of the remaining bacteria to antimicrobial action $[20,21]$.

This controversy has particular relevance in the treatment of meningitis. The blood-brain barrier limits the entry of most antimicrobial agents into the CSF [22]. Even in the presence of inflamed meninges, when a generalized nonspecific increase in membrane permeability allows enhanced drug penetration [23], the therapeutic margin may be small.

Penetration of penicillin into the CSF and other foci of infection has been studied since the introduction of this antimicrobial agent into clinical use [24]. The chemical characteristics of penicillin are major factors limiting its entry into the CSF [25]. Protein binding, acidity, ionization, and lack of a transport system result in slow diffusion across the leptomeninges. Concentration of penicillin in the CSF is further limited by the existence of an active transport process that pumps penicillin out of the CSF and into the serum [26]. Thus the cornerstone of treatment of infections in the CSF has been the parenteral administration of large doses of antibiotic to achieve maximal serum concentrations that enhance diffusion into the infected site [27].

Debate has centered, however, on which mode of administration (continuous infusion or intermittent bolus injection) is most effective in producing high concentrations of antibiotic in CSF and a rapid bactericidal effect in vivo. Plorde et al. [5] examined the kinetics of penicillin penetration through uninflamed and inflamed meninges (aseptic meningitis) of dogs with use of different modes of iv injection of antibiotic. Early in therapy, high levels of penicillin were detected in the CSF only after bolus infusion; however, after several hours of therapy, the levels achieved with continuous infusions were as high as, or even slightly higher than, those produced by bolus infusion. These studies did not include the effect of these differences on the elimination of bacteria from the CSF.

We examined the kinetics of bacterial killing in the CSF in experimental pneumococcal meningitis as a function of the mode of administration of equivalent doses of penicillin. The therapeutic regimens chosen represent those in common clinical usage and achieved serum levels equivalent to those achieved in humans. As in Plorde's studies [5], higher concentrations of penicillin in CSF were detected earlier after intermittent bolus administration than after continuous iv infusion. Despite these differences in concentration, only slight differences in bacterial killing were seen. An enhanced bactericidal effect was seen with intermittent infusion of penicillin early in the treatment period (only between the first and second hours of therapy). This effect probably reflected the higher initial levels of penicillin found in the CSF after bolus administration and thus the earlier initiation of bacterial killing. Over the remaining $6 \mathrm{hr}$ of treatment, the magnitude of bacterial killing (change in log titer) was equivalent for groups of animals receiving both intermittent and continuous dosages.

Despite the low (sub-MIC in 18 of 28 animals) trough levels of penicillin in CSF of animals receiving penicillin by bolus every $4 \mathrm{hr}$, no rebound in bacterial titers was noted during the 1-2 hr when levels of drug were low. This finding is consistent 
with the persistent suppression ( $\leqslant 2 \mathrm{hr}$ ) of bacterial growth noted in vitro after short periods of exposure of test cultures to penicillin (postantibiotic effect) [11].

The rate of bacterial killing did not differ with the modes of therapy. Both continuous and intermittent administration of penicillin resulted in a straight-line logarithmic decrease in bacterial counts, and the decrease was independent of the titer of bacteria in the CSF before treatment. Thus, neither the quantity of bacteria in the initial sample of CSF nor the manner of penicillin administration influenced the rate at which bacteria were killed.

In contrast, the duration of therapy required to sterilize the CSF correlated directly with the initial bacterial titer of the CSF. An 8-hr period of treatment reduced the bacterial count by a mean of 5 $\operatorname{logs}$ and therefore was adequate to sterilize the CSF of rabbits with initial bacterial titers of $<10^{5}$ $\mathrm{cfu} / \mathrm{ml}$. At an equivalent rate of bacterial killing, $50 \%$ of animals with higher initial titers $\left(>10^{5}\right.$ $\mathrm{cfu} / \mathrm{ml}$ ) still had detectable bacterial counts in the CSF at the end of the experiment. A similar observation on the role of initial bacterial titers was made by Feldman [28], who studied humans with meningitis. A higher rate of complications and a slower response to therapy was seen in patients with meningitis whose bacterial titers before treatment exceeded $10^{7} \mathrm{cfu} / \mathrm{ml}$ as compared with the response of patients who had lower CSF titers.

These initial experiments resulted in levels of penicillin in CSF that were at or above the MIC for the test strain for virtually the entire $8 \mathrm{hr}$ of observation. Thus, they are equivalent to in vitro "time-kill curves" with continuous exposure to stable levels of antibiotic. Under these conditions, titers of $S$. pneumoniae continually decline until sterility is achieved during exposure to $0.1,1.0$, or $10 \mu \mathrm{g}$ of ampicillin $/ \mathrm{ml}$. In this situation, and in the experiments with penicillin in this study, a postantibiotic effect cannot be discerned. If, however, the bacteria are exposed to ampicillin for a relatively short period of time, a postantibiotic effect is observed in vitro. In this study, when similar conditions were designed for exposure to ampicillin in the CSF in rabbits with experimental pneumococcal meningitis, a postantibiotic effect was demonstrated in vivo. This phenomenon was observed in all animals.

The effect of ampicillin in experimental men- ingitis was greater than that seen in vitro. The persistent effect of antibiotics on bacteria has been demonstrated in vitro for a number of different species: S. aureus [11-13], S. pneumoniae, Streptococcus [29], and $E$. coli [12]. The results are qualitatively similar for each of these organisms. A postantibiotic effect was observed with several antibiotics including penicillins, cephalosporins, macrolides, chloramphenicol, and vancomycin $[11,12]$. However, the duration of the effect varies (generally 1.5 to $5 \mathrm{hr}$ after a 2 -hr exposure) and is not demonstrable for some agents (e.g., gentamicin). A maximal postantibiotic effect could be achieved by an increase in the duration of exposure to the drug, and the effect was prolonged slightly if the test concentration of drug was increased from one to 10 times the MIC. Similar results were found in this study. A near maximal postantibiotic effect was seen when log-phase $S$. pneumoniae was exposed to ampicillin at the MIC $(0.1 \mu \mathrm{g} / \mathrm{ml})$ for the test strain (figure 5). Further increases in concentration of drug (e.g., 1 or 10 $\mu \mathrm{g} / \mathrm{ml}$ ) did not appreciably augment the duration of the postantibiotic effect.

This study demonstrates that a postantibiotic effect also occurs in vivo (figure 6). This phenomenon could reflect either nonlethal damage done by the drug or continued persistence at the bacterial binding site. Qualitatively, the postantibiotic effect in the CSF was similar to that observed in the parallel in vitro experiments but differed in two important respects: (I) it occurred after exposure to near- or subinhibitory concentrations of ampicillin; and (2) the maximal effect lasted considerably longer.

The in vivo model is obviously more complex than the in vitro situation. Variables such as growth rate of bacteria in the CSF, pharmacokinetics of entry and persistence of drug in the CSF, and various host factors must be considered. In our model the bacterial titer in untreated animals remains essentially unchanged during the first $8 \mathrm{hr}$ of observation. In addition, if the organisms are removed and placed in either fresh broth or sterile CSF, there is a long latent period before titers begin to increase [30]. Therefore, the rate of growth of the bacteria in the CSF in the early stages of disease in this model appears to be slow. However, this phenomenon would be expected to decrease rather than increase the duration of a postantibiotic effect, since the antibacterial activ- 
ity of all $\beta$-lactam antibiotics is greatest in rapidly growing cells.

In this study exposure of $S$. pneumoniae in vivo to near- or subinhibitory concentrations of ampicillin in the CSF $(<0.1 \mu \mathrm{g} / \mathrm{ml})$ for short periods $(<1-3 \mathrm{hr})$ still resulted in an antibacterial effect of 6-7 hr. Some effects of subinhibitory concentrations of antibiotics on bacterial morphology in vitro are well known [13]. In our model, scanning electron microscopy of specimens of CSF aspirated $3 \mathrm{hr}$ after exposure to ampicillin revealed large and aberrant pneumococcal forms. Potentially even more important was the effect of sub-MIC concentrations of antibiotic on the host defense mechanism. When $E$. coli is exposed to chloramphenicol in vitro, an enhancement in bactericidal activity of leukocytes is seen. This postantibiotic effect was dependent on active factors in serum (e.g., antibody and complement) and did not occur at sub-MIC concentrations of chloramphenicol; however, very short exposure times $(10 \mathrm{~min})$ were used [12]. These effects may be due to perturbation of the outer membrane and a change to serum sensitivity [31]. Antibiotics also may alter lysozyme function [32], antibody and complement [15], or phagocytic ability [11, 33, 34]. In addition, pretreatment of staphylococci or streptococci with sub-MICs of penicillin facilitates phagocytic ingestion and killing $[35,36]$. These effects may explain, in part, why the postantibiotic effect was observed in vivo in our experiments at near to subMIC levels of ampicillin in the CSF when similar results have not been apparent in other in vitro experiments $[11,12]$. The fact that the postantibiotic effect is of longer duration in vivo and is achieved with relatively short, low-level exposure to ampicillin may reflect the contribution of host defense mechanisms.

The results outlined in these studies may have important clinical relevance. The highest immediate concentrations of penicillin in the CSF were achieved after the injection of a bolus, and this correlated with a significant, but small, enhancement in early bactericidal effect. Thus, in a critically ill adult patient (with normal renal function) with pneumonococcal meningitis, a therapeutic advantage might be gained by the initial administration of penicillin by iv bolus (1-2 $\times 10^{6}$ units) followed by either mode of drug delivery for a total of $2.0 \times 10^{7}$ units daily. The clinical relevance of the postantibiotic effect observed in vivo is not known at this time. However, even sub-MIC levels of drug in the CSF produced this phenomenon, a fact that may be of importance in the results of diagnostic procedures in partially treated outpatients receiving orally administered drugs and in the therapeutic results obtained when antibiotics are administered intermittently in full doses. The results of a study of single, large-dose penicillin therapy of meningococcal meningitis in Africa tend to support this concept [37].

\section{References}

1. Eagle, H., Fleischman, R., Musselman, A. D. The effective concentrations of penicillin in vitro and in vivo for streptococci, pneumococci, and Treponema pallidum. J. Bacteriol. 59:625-643, 1950.

2. Eagle, H., Fleischman, R., Musselman, A. D. Effect of schedule of administration on the therapeutic efficacy of penicillin: importance of the aggregate time penicillin remains at effectively bactericidal levels. Am. J. Med. 9:280-299, 1950.

3. Schmidt, L. H., Walley, A. The influence of the dosage regimen on the therapeutic effectiveness of penicillin $\mathrm{G}$ in experimental lobar pneumonia. J. Pharmacol. Exp. Ther. 103:479-488, 1951.

4. Barza, M., Brusch, J., Bergeron, M. G. Weinstein, L. Penetration of antibiotics into firbrin loci in vivo. III. Intermittent vs. continuous infusion and the effects of probenecid. J. Infect. Dis. 129:73-78, 1974.

5. Plorde, J. J., Garcia, M., Petersdorf, R. G. Studies on the pathogenesis of meningitis. IV. Penicillin levels in the cerebrospinal fluid in experimental meningitis. J. Lab. Clin. Med. 64:960-969, 1964.

6. Meads, M., Harris, H. W., Finland, M. Treatment of pneumococcal pneumonia with penicillin. N. Engl. J. Med. 232:747-755, 1945.

7. Weinstein, L., Daikos, G. The treatment of scarlet fever with crystalline penicillin $G$ administered orally or parenterally twice a day. Am. Pract. Digest Treatment 2:60-64, 1951.

8. Eagle, H., Fleischman, R., Levy, M. "Continuous" vs. "discontinuous" therapy with penicillin. N. Engl. J. Med. 248:481-488, 1953.

9. Parker, R. F., Marsh, H. C. Action of penicillin on Staphylococcus. J. Bacteriol. 51:181-186, 1946.

10. Parker, R. F., Luse, S. The action of penicillin on Staphylococcus: further observations on the effect of a short exposure. J. Bacteriol. 56:75-81, 1948.

11. McDonald, P. J., Craig, W, A., Kunin, C. M. Persistent effect of antibiotics on Staphylococcus aureus after exposure for limited periods of time. J. Infect. Dis. 135:217-223, 1977.

12. Pruul, H., McDonald, P. J. Enhancement of leukocyte activity against Escherichia coli after brief exposure to chloramphenicol. Antimicrob. Agents. Chemother. $1 \overline{6}: 695-700,1979$

13. Lorian, V. Some effects of subinhibitory concentrations of 
antibiotics on bacteria. Bull. N.Y. Acad. Med. 51: 1046-1055, 1975.

14. Friedman, H., Warren, G. H. Enhanced susceptibility of penicillin-resistant staphylococci to phagocytosis after in vitro incubation with low doses of nafcillin. Proc. Soc. Exp. Biol. Med. 146:707-711, 1974.

15. Friedman, H., Warren, G. H. Antibody-mediated bacteriolysis: enhanced killing of cyclacillin-treated bacteria. Proc. Soc. Exp. Biol. Med. 153:301-304, 1976.

16. Sherertz, R. J., Dacey, R., Sande, M. A. Cefamandole in the therapy of experimental pneumococcal meningitis. J. Antimicrob. Chemother. 2:159-165, 1976.

17. Sande, M. A., Sherertz, R. J., Zak, O., Strausbaugh, L. J. Cephalosporin antibiotics in therapy of experimental Streptococcus pneumoniae and Haemophilus influenzae meningitis in rabbits. J. Infect. Dis. (Suppl.) 137:S161-S168, 1978.

18. Bennett, J. V., Brodie, J. L., Benner, E. J., Kirby, W. M. M. Simplified accurate method for antibiotic assay of clinical specimens. Applied Microbiology $14: 170-177,1966$.

19. Gerber, I. E., Shwartzman, G., Baehr, G. Penetration of penicillin into foci of infection. J.A.M.A. 130:761-764, 1946.

20. Bigger, J. W. Treatment of staphylococcal infections with penicillin by intermittent sterilization. Lancet 2:497$500,1944$.

21. McDermott, W. Microbial persistence. Yale J. Biol. Med. 30:257-291, 1958.

22. Barlow, C. R. Clinical aspects of the blood-brain barrier. Annu. Rev. Med. 15:187-202, 1964.

23. Ruedy, J. The concentrations of penicillins in the cerebrospinal fluid and brain of rabbits with experimental meningitis. Can. J. Physiol. Pharmacol. 43:763-772, 1965.

24. Dumoff-Stanley, E., Dowling, H. F., Sweet, L. K. The absorption into and distribution of penicillin in cerebrospinal fluid. J. Clin. Invest. 25:87-93, 1946.

25. Schanker, L. S. Passage of drugs across body membranes. Pharmacol. Rev. 14:501-530, 1962.

26. Fishman, R. A. Blood brain and CSF barriers to penicillin and related organic acids. Arch. Neurol. $15: 113-124,1966$.
27. Dowling, H. F., Sweet, L. K. Robinson, J. A., Zellers, W. W., Hirsh, H. L. The treatment of pneumococcal meningitis with massive doses of systemic penicillin. Am. J. Med. Sci. 217:149-156, 1949.

28. Feldman, W. E. Relation of concentrations of bacteria and bacterial antigen in cerebrospinal fluid to prognosis in patients with bacterial meningitis. N. Engl. J. Med. 296:433-435, 1977.

29. Eagle, H., Musselman, A. D. The slow recovery of bacteria from the toxic effects of penicillin. J. Bacteriol. 58:475-490, 1949.

30. Strausbaugh, L. J., Sande, M. A. Factors influencing the therapy of experimental Proteus mirabilis meningitis in rabbits. J. Infect. Dis. 137:251-260, 1978.

31. Reynolds, B. L., Pruul, H. Sensitization of complementresistant smooth gram-negative bacterial srains. Infect. Immun. 3:365-372, 1971.

32. Warren, G. H., Gray, J. Effect of sublethal concentrations of penicillins on the lysis of bacteria by lysozyme and trypsin. Proc. Soc. Exp. Biol. Med. 120:504-511, 1965.

33. Adam, D., Schaffert, W., Marget, W. Enhanced in vitro phagocylosis of Listeria monocytogenes by human monocytes in the presence of ampicillin, tetracycline and chloramphenicol. Infect. Immun. 9:811-814, 1974.

34. Nishida, M., Mine, Y., Nonoyama, S., Yokota, Y. Effect of antibiotics on the phagocytosis and killing of Pseudomonas aeruginosa by rabbit polymorphonuclear leukocytes. Chemotherapy 22:203-210, 1976.

35. Yourtee, E., Metcalf, J. A., Root, R. K. Augmented killing of penicillin pretreated $S$. aureus by human neutrophils: role of complement [abstract]. Clin. Res. 28: 383A, 1980.

36. Isturiz, R., Metcalf, J. A., Root, R. K. Augmented killing of streptococci by human neutrophils after penicillin pretreatment [abstract]. Clin. Res. 28:512A, 1980.

37. MacFarlane, J. T., Anjorin, F. I., Cleland, P. G., HassanKing, M., Tor-Agbidye, S., Wali, S. S., Weir, W. R. C., Whittle, H. C., Yahaya, H. N., Greenwood, B. M. Single injection treatment of meningococcal meningitis. 1. Long-acting penicillin. Trans. R. Soc. Trop. Med. Hyg. 73:693-697, 1979. 